\title{
Effect of Salinity and Low Osmotic Potential on the Germination and Seedling Growth of Rapeseed Cultivars with Different Stress Tolerance
}

\author{
Roberta Pace* and Paolo Benincasa \\ Dipartimento di Scienze Agrarie ed Ambientali, Università di Perugia, \\ Borgo XX Giugno 74, 06121 Perugia, Italy
}

Received: 14 September 2009. Accepted: 26 November 2009.

\begin{abstract}
In mediterranean environments, rapeseed is grown in fall-winter with late-summer sowing and this implies that germination and initial seedling growth may occur in soils with low water content and/or high salinity.

Lab experiments were carried out to study the effect of the level and timing of salt and osmotic stress application on the germination and seedling growth of rapeseed (Brassica napus var. oleifera Del.) cultivars with different stress tolerance. After a preliminary screening on eighteen cultivars, four hybrids with different stress tolerance during germination were chosen to study germination on Petri dishes at 14 increasing concentrations of PEG 6000 ( $\psi$ s up to $-1.5 \mathrm{MPa}$ ) and 12 increasing concentrations of $\mathrm{NaCl}$ (up to $600 \mathrm{mM}$ ). Seedlings from seeds germinated at 0 and $250 \mathrm{mM}$ of $\mathrm{NaCl}$ were then grown into boxes for the slant test containing $\mathrm{NaCl}$ solutions $0 \mathrm{mM}$ and $100 \mathrm{mM}$, while seedlings from seeds germinated -0.8 and $-0.03 \mathrm{MPa}$ (PEG) were grown in pots containing siliceous sand with a water content equivalent to field capacity or half of field capacity. In both experiments seedlings were grown for 11 days under controlled light/temperature conditions. Therefore, for both salt and osmotic stress experiments, the following four combinations for "germination-growth" conditions were obtained for each cultivar: optimum-optimum; optimum-stress; stress-optimum; stress-stress. The following determinations were performed: final percentage germination, time to $50 \%$ germination (T50), and base water potential of seeds; dry and fresh weights, and shoot and root lengths of seedlings at the end of the growth period (i.e. 11 days after plant transfer to the growth medium), and correspondent relative growth rates between the start and the end of the growth period.

The different degree of stress tolerance observed among rapeseed cultivars for germination was in the order of 150 $\mathrm{mMol}$ for $\mathrm{NaCl}$ concentration and 0.2-0.3 MPa for osmotic potential. Nonetheless, cultivars did not differ substantially for growth parameters of seedlings exposed to stressing conditions, and in some cases cultivars with higher tolerance during germination resulted even more sensitive during growth, especially under salt stress. The severe stresses applied reduced seedling growth, and root more than shoot growth. Agronomic implications for the different stress tolerance of cultivars are discussed.
\end{abstract}

Key-words: base water potential, Brassica napus, $\mathrm{NaCl}$, polyethylene glycol, screening.

\section{Introduction}

In mediterranean environments, rapeseed is grown in the fall-spring period and sown in late summer-early autumn to allow plants achieve a suitable developmental stage to guarantee a good cold resistance before the start of winter frost. This implies that germination and initial seedling growth may occur in soils with low water content and high salinity (especially in case of coastal regions) (Anastasi et al., 2003). This may cause delayed and reduced germination and seedling growth, with negative effects on crop establishment, crop-weed competition, and final grain yield (Blackshaw, 1991; Al-Thabet et al., 2004; Willenborg et al., 2004; Andalibi et al., 2005). Both drought and salinity reduce seed imbibition because of the lowered soil water potential. In addition salinity may cause a toxic effect due to accumulation of ions (e.g. $\mathrm{Na}^{+}$and $\mathrm{Cl}$ ) in the cytoplasm (Kafkafi and Bernstein, 1996). Once a seed has germinated, water and salt stress may reduce seedling growth (Tei and Ciriciofolo, 
1997; Athar and Ashraf, 2005; Kauser et al., 2006), although in case of salinity ions uptake and cytoplasmic or vacuolar ion compartmentation (Blumwald, 2000) may partly mask the reduction of organic matter accumulation in seedlings. Both stresses would reduce shoot more than root growth mainly due to the osmotic component (Munns, 2002) and actually many studies on water and salt stresses in Brassica species report a decrease of the shoot/root ratio (Maggio et al., 2004; Badruddin et al., 2005; Jamil et al., 2005), although there are also opposite evidences for salt stress (Jamil et al., 2006).

The genotype may play a crucial role in crop establishment under salt and water stressing conditions. It is known that in optimal conditions, cultivars may differ much for germination rate and final \% germination (King et al., 1986), but performances might be altered in case of stressing conditions. Moreover, the stress tolerance (or sensitivity) of one cultivar during germination might not necessarily imply a concordant level of tolerance (or sensitivity) during the next growth phases. On the other hand the germination condition may affect the next seedling and plant growth (Ungar, 1995). Thus, for example, a seed germinated in stressing condition might have been damaged or hardened and as a consequence the seedling growth in either stressing or optimal conditions might be worsened or improved. Due to the very variable rainfall regime in late summer-early autumn in mediterranean climates, the crop may experiment all the possible combinations of soil water availability (and thus saline concentration of the soil solution) in the "germination-initial growth" phases: the soil might be constantly dry (and likely saline) or constantly wet (and likely less saline) during both germination and seedling growth, but it might also be dry during germination and then wet during initial seedling growth thanks to a rainfall, or the reverse might happen if an occasional rainfall occurs before sowing not followed by other rainfalls in the next weeks.

The present research was carried out to study the effect of the level and timing of salt and water stresses application on the germination and initial growth of rapeseed cultivars with different stress tolerance.

\section{Materials and methods}

A preliminary screening was carried out on seeds from 18 cultivars of rapeseed (Brassica napus var. oleifera Del.) either hybrids or synthetic varietes provided by different companies (see legend in Fig. 1) in order to identify cultivars with different stress tolerance during germination. For each cultivar three replicates represented by 9 -cm-diameter Petri dishes of 50 seeds each were incubated on absorbent paper (filter paper circles, $8.5 \mathrm{~cm}$ diameter, Whatman Grade 1) saturated with PEG 6000 solutions equivalent to osmotic potentials of $-0.7,-0.8,-0.9$

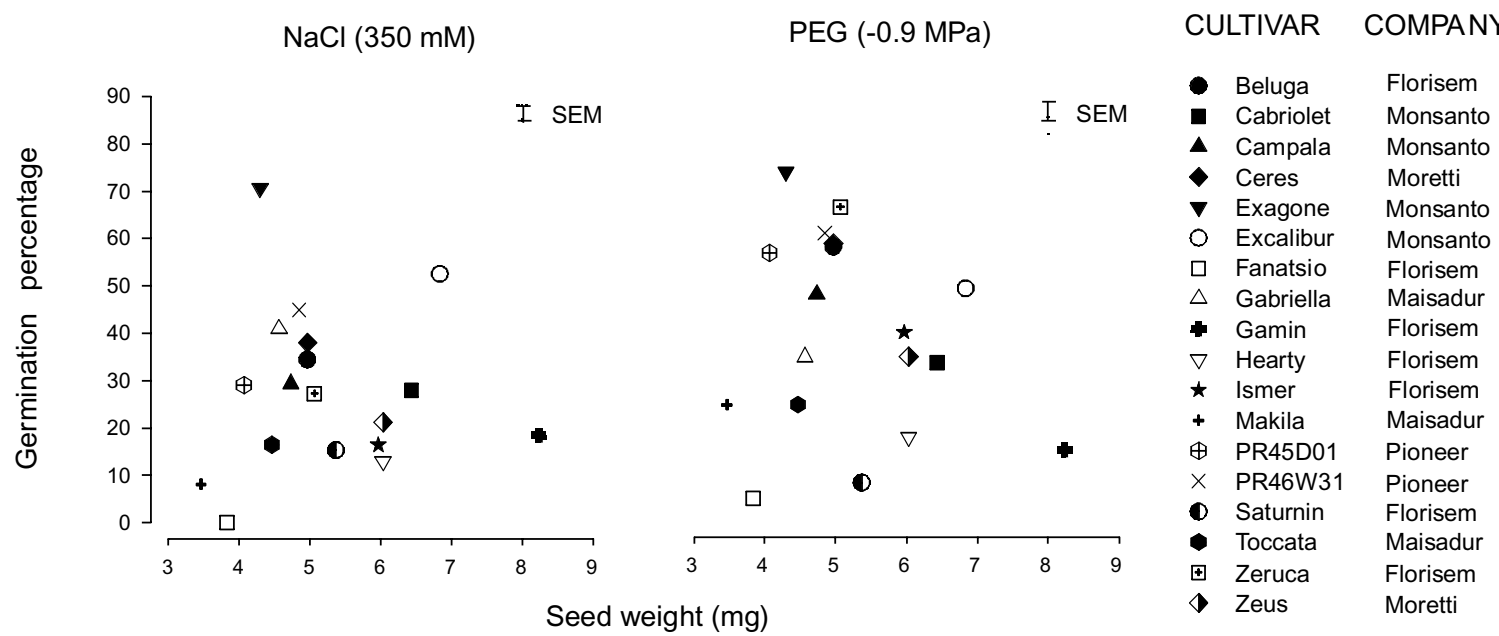

Figure 1. Arcsin square root transformed data of final percentage germination for seeds from the eighteen rapeseed cultivars subjected to preliminary screening for tolerance to A) salinity ( $\mathrm{NaCl} 350 \mathrm{mM}$ ) and B) low osmotic potential $(-0.9 \mathrm{MPa})$ of the solutions used to saturate the germination substrate. Values are means of 3 replicates. 
and -1.0 MPa or with $\mathrm{NaCl}$ solutions 250,300,350, $400 \mathrm{mM}$ plus a control saturated with distilled water (i.e. $0 \mathrm{MPa}$ and $0 \mathrm{mM} \mathrm{NaCl}$ ). Dishes were placed in a controlled-temperature chamber at darkness at $20^{\circ} \mathrm{C}$. Germinated seeds were counted everyday until 14 days from the start of the experiment and the final percentage germination was taken as indicator of stress tolerance degree. A seed was considered germinated when radicle extrusion was greater than $2 \mathrm{~mm}$.

Among the eighteen cultivars, four hybrids Exagone and Excalibur (Monsanto), tolerant to both stresses, and Toccata (Maisadour Semences) and Saturnin (Florisem), sensitive to both stresses during germination were chosen to deepen the study on germination at 13 increasing concentrations of PEG 6000 solutions (equivalent to $-0.03,-0.15,-0.3,-0.4,-0.5,-0.6,-0.7,-0.8,-0.9$, $-1,-1.1,-1.2,-1.5 \mathrm{MPa})$ and 12 increasing concentrations of $\mathrm{NaCl}(0,50,100,150,200,250$, $275,300,325,350,400,500,600 \mathrm{mM}$ ), plus a control saturated with distilled water (i.e. $0 \mathrm{MPa}$ and $0 \mathrm{mM} \mathrm{NaCl}$ ). The number of germinated seeds was counted every day until 14 days from the start of the experiment and used to calculate the percentage germination. The time to reach $50 \%$ germination (T50) was calculated according to Coolbear et al. (1984). The base water potential $\left(\psi_{\mathrm{b}}\right)$ was calculated according to Bradford (1995), considering the intercepts on $\mathrm{x}$ axis of the regression lines describing the variation of the germination rate $\left(\mathrm{d}^{-1}\right)$ with water potential for each germination percentile.

For the salt stress experiment, seedlings from seeds germinated at 0 and $250 \mathrm{mM}$ of $\mathrm{NaCl}$ were then transferred in plexiglass boxes with drilled lid and walls ( 21 holes of $3 \mathrm{~mm} \varnothing$ ) for slant test (Wurr and Fellows, 1985) containing distilled water $(0 \mathrm{mM})$ or a $\mathrm{NaCl}$ solution $(100$ $\mathrm{mM})$, both added with Flory 9 (Agrimport), a liquid fertilizer for hydroponics. Seedlings were placed $1 \mathrm{~cm}$ apart in a horizontal row along the long axis of $10 \times 16 \mathrm{~cm}$ rectangular piece of Whatman ${ }^{\circledR}$ n. 1 chromatography paper held on $10 \times 18.5 \mathrm{~cm}$ clear plastic plate $3 \mathrm{~mm}$ thick. The plate was held at an angle of $20^{\circ}$ from the vertical by a slotted rack in the base $20 \times 30 \mathrm{~cm}$ seed tray. The chromatography paper was kept moist by dipping into solution in the tray. Each plate held up to 10 seedlings and each tray held 10 plates for a total of 100 seedlings per box.

Similarly, for water stress experiment, seedlings from seeds germinated in PEG solutions at -0.03 and $-0.8 \mathrm{MPa}$ were then transferred in pots (10 per pot) containing $81 \mathrm{~g}$ of siliceous sand with a water content equivalent to field capacity (optimum) or half of field capacity (stress). The pots were contained in plexiglass boxes (12 per box) with a drilled lid (the same used in slant test experiment for salt stress) and were watered regularly every 2 days to restore initial water content.

Therefore, for both salt and water stress experiments, the following four combinations for "germination-growth" conditions were obtained for each cultivar: optimum-optimum $(\mathrm{O}-\mathrm{O})$; optimum-stress (O-S); stress-optimum (S-O); stress-stress (S-S). The lower concentration of $\mathrm{NaCl}$ in the growth medium $(100 \mathrm{mM})$ with respect to that of the germination medium (250 $\mathrm{mM}$ ) was necessary because concentration higher than $100 \mathrm{mM}$ caused weakness and death of most seedlings few days after plant transfer.

For both salt and water stress experiments, the boxes were placed in a growing room for 11 days at day/night temperature of $25 / 15^{\circ} \mathrm{C}$ with a photoperiod of 14 hour light and $10 \mathrm{~h}$ darkness.

A randomized block design with three replicates (boxes) per treatment (cultivar x growing conditions) was adopted.

The root and shoot lengths and the total plant fresh and dry weights of seedlings were measured at regular intervals until 11 days after seedling transfer to the growth medium and the correspondent relative growth rates (RGRs) were calculated between the start and the end of the growth period (i.e. between 0 and 11 days after seedling transfer to the growth medium).

\section{Statistical analysis}

Data on germination and seedling growth were analyzed by Student's $t$-test. Means were compared between cultivars and treatments by LSD (least significant difference) at the 0.05 confidence level. Percentage data were arcsin square root transformed for analysis and graphs. Back transformed means are given in the text wherever appropriate.

\section{Results}

All the cultivars subjected to the preliminary screening had very high percentage germination 
Table 1. Number of days needed to reach $50 \%$ germination (T50) for the four rapeseed cultivars sown on filter paper saturated with distilled water (Control) and with solutions at increasing concentrations of $\mathrm{NaCl}(250,325,350,400)$ and PEG (corresponding to $\psi \mathrm{s}=-0.7,-0.8,-0.9,-1.0 \mathrm{MPa}$ ). Values are means of 3 replicates.

\begin{tabular}{|c|c|c|c|c|c|c|c|c|c|}
\hline \multirow[t]{3}{*}{ Cultivar } & \multicolumn{8}{|c|}{ T50 (d) } & \\
\hline & \multirow{2}{*}{$\begin{array}{c}\text { Control } \\
0 \\
\end{array}$} & \multicolumn{4}{|c|}{$\mathrm{NaCl}(\mathrm{mM})$} & \multicolumn{4}{|c|}{ PEG (MPa) } \\
\hline & & 250 & 325 & 350 & 400 & -0.7 & -0.8 & -0.9 & -1.0 \\
\hline Exagone & 2.5 & 2.5 & 2.5 & 2.6 & 5.2 & 2.8 & 4.1 & 5.1 & 8.2 \\
\hline Excalibur & 2.5 & 2.5 & 4.3 & 6.0 & 7.3 & 2.9 & 4.4 & 5.9 & 8.9 \\
\hline Toccata & 2.5 & 2.9 & 6.2 & 6.7 & 6.9 & 4.3 & 6.9 & 8.0 & - \\
\hline Saturnin & 2.5 & 2.6 & 6.5 & 6.6 & 9.2 & 3.8 & 6.6 & 8.0 & - \\
\hline
\end{tabular}

LSD $(\mathrm{P}=0.05 ;$ d.f. $=40): \mathrm{NaCl}=2.99 ; \mathrm{PEG}=2.01$

(> 93\%, data not shown) in non stressing conditions, while they showed a much different response under salt and osmotic stress. The maximum variability of responses between cultivars was observed at the saline concentration of 350 $\mathrm{mM}$ and the water potential of $-0.9 \mathrm{MPa}$, with no relation with seed weight (Fig. 1). Exagone, Excalibur, PR46W31 and Ceres resulted quite tolerant to both stresses, Fantasio, Makila, Toccata, Saturnin, Hearty, Gamin quite sensitive (Fig. 1).

Increasing salinity and osmotic potential reduced T50 and final percentage germination in all the four hybrids used to continue the experiment, but the effect was much greater in Saturnin and Toccata than in Exagone and Excalibur (Tab. 1, Fig. 2). Exagone was the most tolerant to both stresses, Saturnin the most sensitive. These two cultivars also showed a much different base water potential $\left(\psi_{\mathrm{b}}\right)$, that ranged between -1.207 and -1.036 MPa in Exagone and between -0.887 and $-0.853 \mathrm{MPa}$ in Saturnin (Fig. 3). Based on percentage germination, T50 and $\psi_{\mathrm{b}}$, differences between these two cultivars were in the order of $150 \mathrm{mM}$ for $\mathrm{NaCl}$ and $0.2-0.3$ MPa for PEG (Figg. 2 and 3, Tab. 1). Excalibur

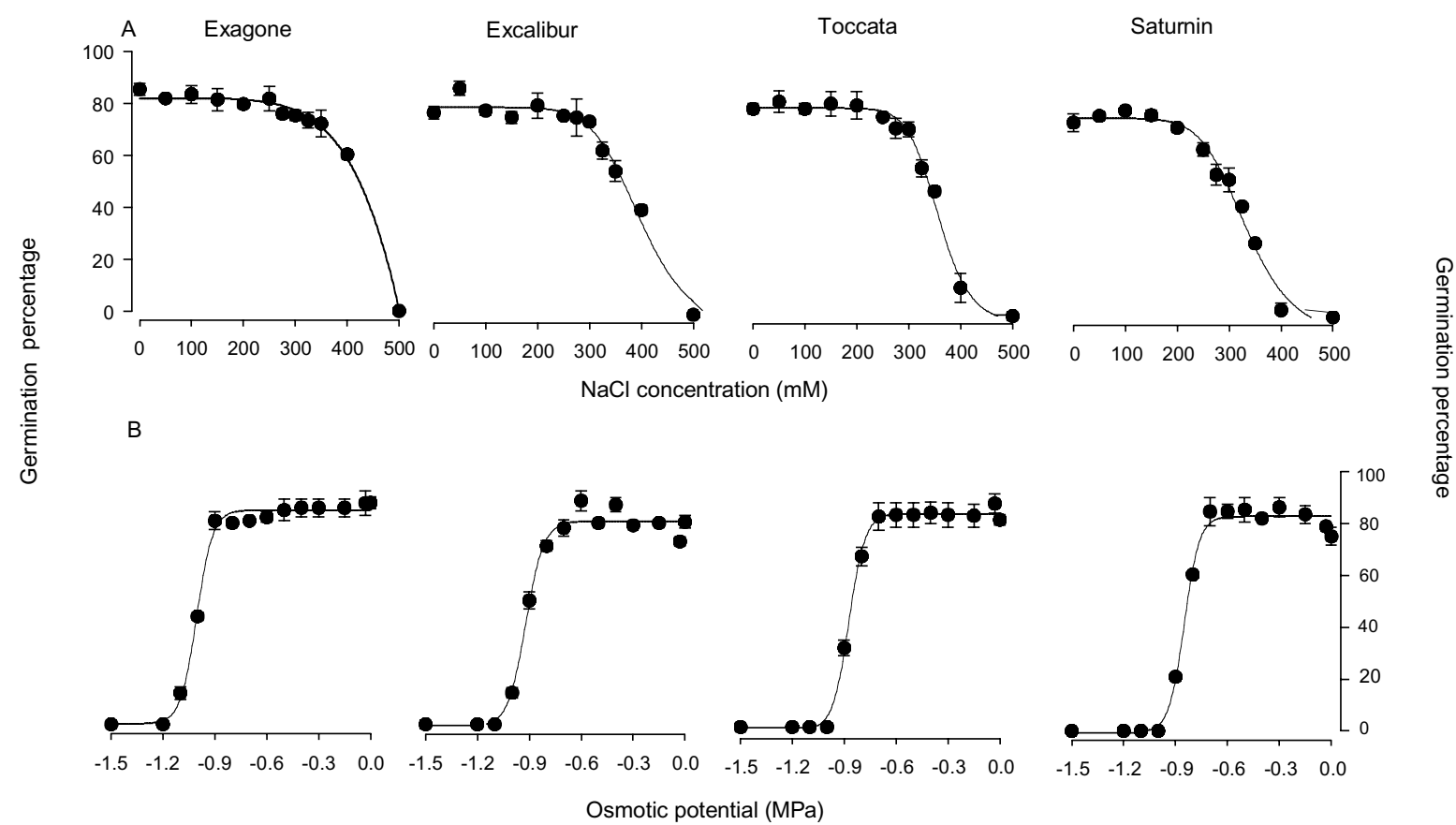

Figure. 2. Arcsin square root transformed data of final percentage germination for seeds from the the four rapeseed cultivars Exagone, Excalibur, Toccata and Saturnin subjected to increasing $\mathrm{NaCl}$ concentrations (A) and decreasing osmotic potential (B) of the solutions used to saturate the germination substrate. Values are means of 3 replicates. Bars indicate SEs. 
Table 2. Total dry and fresh weights $(\mathrm{mg})$ and shoot and root lengths $(\mathrm{mm})$ of seedlings from the four rapeseed cultivars at 11 days after seedling transfer to the growth medium for the four combinations of "germination-growth" conditions $(\mathrm{O}-\mathrm{O}$, $\mathrm{O}$ $\mathrm{S}, \mathrm{S}-\mathrm{O}, \mathrm{S}-\mathrm{S}$ ) for both salinity and osmotic potential. In the experiment on salinity, O (optimum) corresponds to $0 \mathrm{mM} \mathrm{NaCl}$ for both germination and growth conditions, $\mathrm{S}$ (stress) corresponds to $250 \mathrm{mM} \mathrm{NaCl}$ for germination and $100 \mathrm{mM} \mathrm{NaCl}$ for growth; in the experiment on osmotic potential, $\mathrm{O}$ corresponds to $-0.03 \mathrm{MPa}$ for germination and to field capacity for growth, $\mathrm{S}$ corresponds to $-0.8 \mathrm{MPa}$ for germination and to half of field capacity for growth. Values are means of 3 replicates.

\begin{tabular}{|c|c|c|c|c|c|c|c|c|}
\hline \multirow[t]{2}{*}{ Cultivar } & \multicolumn{4}{|c|}{ Salinity } & \multicolumn{4}{|c|}{ Osmotic potential } \\
\hline & $\mathrm{O}-\mathrm{O}$ & $\mathrm{O}-\mathrm{S}$ & $\mathrm{S}-\mathrm{O}$ & S-S & $\mathrm{O}-\mathrm{O}$ & $\mathrm{O}-\mathrm{S}$ & $\mathrm{S}-\mathrm{O}$ & S-S \\
\hline \multicolumn{9}{|c|}{ Total plant dry weight (mg) } \\
\hline Exagone & 5.9 & 3.5 & 5.0 & 3.1 & 5.0 & 4.1 & 5.0 & 3.1 \\
\hline Excalibur & 7.2 & 4.8 & 6.6 & 4.2 & 7.0 & 6.3 & 6.3 & 5.1 \\
\hline Toccata & 8.2 & 4.8 & 5.0 & 3.6 & 4.8 & 3.9 & 4.7 & 3.1 \\
\hline Saturnin & 7.3 & 4.4 & 6.2 & 5.1 & 4.4 & 3.8 & 4.0 & 3.7 \\
\hline \multicolumn{9}{|c|}{ Total plant fresh weight (mg) } \\
\hline Exagone & 179 & 82 & 109 & 36 & 95 & 88 & 103 & 81 \\
\hline Excalibur & 162 & 76 & 131 & 51 & 132 & 145 & 126 & 102 \\
\hline Toccata & 218 & 87 & 118 & 61 & 85 & 54 & 73 & 49 \\
\hline Saturnin & 159 & 86 & 107 & 54 & 93 & 92 & 84 & 77 \\
\hline \multicolumn{9}{|c|}{ Shoot lenght $(\mathrm{mm})$} \\
\hline Exagone & 68 & 22 & 47 & 14 & 60 & 59 & 73 & 68 \\
\hline Excalibur & 88 & 30 & 61 & 30 & 68 & 63 & 80 & 63 \\
\hline Toccata & 64 & 28 & 49 & 13 & 66 & 61 & 68 & 56 \\
\hline Saturnin & 67 & 33 & 45 & 13 & 60 & 48 & 67 & 50 \\
\hline \multicolumn{9}{|c|}{ Root lenght (mm) } \\
\hline Exagone & 88 & 26 & 41 & 7 & 102 & 95 & 99 & 94 \\
\hline Excalibur & 113 & 27 & 40 & 11 & 124 & 92 & 117 & 105 \\
\hline Toccata & 97 & 34 & 54 & 6 & 105 & 94 & 94 & 80 \\
\hline Saturnin & 110 & 41 & 48 & 5 & 121 & 73 & 118 & 102 \\
\hline
\end{tabular}

LSD $(\mathrm{P}=0.05 ;$ d.f. = 32): Dry weight: $\mathrm{NaCl}=1.77 ; \mathrm{PEG}=1.24 ;$ Fresh weight: $\mathrm{NaCl}=41.4 ; \mathrm{PEG}=17.7$; Shoot lenght: $\mathrm{NaCl}=11.9$; $\mathrm{PEG}=22.2 ;$ Root lenght: $\mathrm{NaCl}=11.6 ; \mathrm{PEG}=22.9$

showed a quite good performance in both stressing conditions, Toccata a quite bad one.

Concerning the seedling growth, differences between cultivars at 11 days after seedling trans-

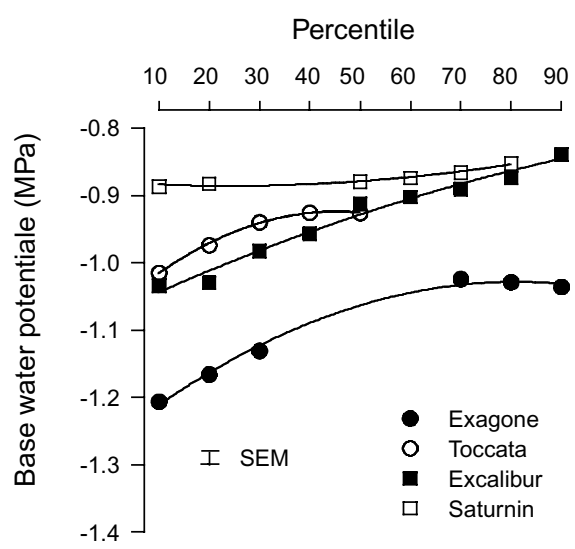

Figure 3. Base water potential for the germination percentiles of seeds from four rapeseed cultivars Exagone, Excalibur, Toccata and Saturnin. fer to the growth medium were small and often not significant for any of the four combinations of "germination-growth" conditions in both salt and osmotic stress treatments (Tab. 2). The total plant dry and fresh weights (Tab. 2) were generally the highest in treatment $\mathrm{O}-\mathrm{O}$, and the lowest in S-S in both stressing conditions. Treatments $\mathrm{S}-\mathrm{O}$ and $\mathrm{O}-\mathrm{S}$ showed intermediate values, except for total plant fresh weights in the experiment with osmotic potential that were close to values observed in O-O. The effect of salinity was much greater than that of osmotic potential and in most cases treatment S-O performed better than treatment O-S. The growth of Exagone was markedly depressed under stress, even more than that of Saturnin. In particular, in Exagone the final dry weight of seedlings for the ever stressed control (S-S) was reduced by $47 \%$ (salinity) and $38 \%$ (osmotic potential) as compared to the dry weight of the never stressed control (O-O), while in Saturnin 
Table 3. Relative Growth Rates (RGRs) between the start and the end of the growth period (i.e. between 0 and 11 days after seedling transfer to the growth medium) calculated on the basis of total dry and fresh weights and shoot and root lengths of seedlings from the four rapeseed cultivars for the four combinations of "germination-growth" conditions (O-O, O-S, S-O, SS) for both salinity and osmotic potential. In the experiment on salinity, $\mathrm{O}$ (optimum) corresponds to $0 \mathrm{mM} \mathrm{NaCl}$ for both germination and growth conditions, $\mathrm{S}$ (stress) corresponds to $250 \mathrm{mM} \mathrm{NaCl}$ for germination and $100 \mathrm{mM} \mathrm{NaCl}$ for growth; in the experiment on osmotic potential $\mathrm{O}$, corresponds to $-0.03 \mathrm{MPa}$ for germination and to field capacity for growth, $\mathrm{S}$ corresponds to $-0.8 \mathrm{MPa}$ for germination and to half of field capacity for growth. Values are means of 3 replicates.

\begin{tabular}{|c|c|c|c|c|c|c|c|c|}
\hline \multirow[t]{2}{*}{ Cultivar } & \multicolumn{4}{|c|}{ Salinity } & \multicolumn{4}{|c|}{ Osmotic potential } \\
\hline & $\mathrm{O}-\mathrm{O}$ & $\mathrm{O}-\mathrm{S}$ & $\mathrm{S}-\mathrm{O}$ & S-S & $\mathrm{O}-\mathrm{O}$ & $\mathrm{O}-\mathrm{S}$ & $\mathrm{S}-\mathrm{O}$ & S-S \\
\hline \multicolumn{9}{|c|}{ RGR on total plant dry weight $\left(\mathrm{mg} \mathrm{mg}^{-1} \mathrm{~d}^{-1}\right)$} \\
\hline Exagone & 0.054 & 0.006 & 0.032 & -0.016 & 0.044 & 0.025 & 0.025 & -0.024 \\
\hline Excalibur & 0.029 & 0.021 & 0.015 & -0.034 & 0.015 & 0.003 & -0.012 & -0.033 \\
\hline Toccata & 0.071 & 0.018 & 0.026 & -0.008 & 0.054 & 0.034 & 0.029 & -0.012 \\
\hline Saturnin & 0.073 & 0.024 & 0.030 & 0.012 & 0.044 & 0.031 & -0.012 & -0.020 \\
\hline \multicolumn{9}{|c|}{ RGR on total plant fresh weight $\left(\mathrm{mg} \mathrm{mg}^{-1} \mathrm{~d}^{-1}\right)$} \\
\hline Exagone & 0.147 & 0.069 & 0.149 & 0.032 & 0.101 & 0.094 & 0.211 & 0.180 \\
\hline Excalibur & 0.123 & 0.047 & 0.164 & 0.069 & 0.093 & 0.094 & 0.194 & 0.173 \\
\hline Toccata & 0.162 & 0.064 & 0.166 & 0.086 & 0.113 & 0.106 & 0.202 & 0.184 \\
\hline Saturnin & 0.137 & 0.076 & 0.168 & 0.101 & 0.109 & 0.057 & 0.187 & 0.177 \\
\hline \multicolumn{9}{|c|}{ RGR on shoot lenght $\left(\mathrm{mm} \mathrm{mm}^{-1} \mathrm{~d}^{-1}\right)$} \\
\hline Exagone & 0.126 & 0.012 & 0.212 & 0.087 & 0.112 & 0.110 & 0.339 & 0.326 \\
\hline Excalibur & 0.104 & 0.020 & 0.250 & 0.115 & 0.124 & 0.117 & 0.303 & 0.279 \\
\hline Toccata & 0.157 & 0.046 & 0.255 & 0.171 & 0.137 & 0.127 & 0.358 & 0.346 \\
\hline Saturnin & 0.137 & 0.065 & 0.272 & 0.145 & 0.166 & 0.142 & 0.286 & 0.256 \\
\hline \multicolumn{9}{|c|}{ RGR on root lenght $\left(\mathrm{mm} \mathrm{mm}^{-1} \mathrm{~d}^{-1}\right)$} \\
\hline Exagone & 0.044 & -0.076 & 0.100 & -0.079 & 0.070 & 0.066 & 0.183 & 0.177 \\
\hline Excalibur & 0.063 & -0.041 & 0.168 & -0.058 & 0.112 & 0.109 & 0.196 & 0.183 \\
\hline Toccata & 0.067 & -0.075 & 0.101 & -0.046 & 0.111 & 0.085 & 0.225 & 0.1970 \\
\hline Saturnin & 0.086 & -0.014 & 0.167 & -0.065 & 0.153 & 0.099 & 0.240 & 0.226 \\
\hline
\end{tabular}

LSD $(\mathrm{P}=0.05$; d.f. = 32): Dry weight: $\mathrm{NaCl}=0.0325 ; \mathrm{PEG}=0.0235$; Fresh weight: $\mathrm{NaCl}=0.0467 ; \mathrm{PEG}=0.0195$; Shoot lenght: $\mathrm{Na}-$ $\mathrm{Cl}=0.0384 ; \mathrm{PEG}=0.0123 ;$ Root lenght: $\mathrm{NaCl}=0.0361 ; \mathrm{PEG}=0.0196$

the decrease of plant dry weight due to salt and osmotic stress was of $30 \%$ and $15 \%$ (not significant), respectively. However, differences between cultivars were smaller and often not significant for the fresh weights of any stressed treatment (i.e. O-S, S-O and S-S) as compared to the fresh weight of $\mathrm{O}-\mathrm{O}$, especially in the experiment on osmotic potential.

Stresses reduced total seedling length, and root more than shoot length (Tab. 2). In particular, the root length was dramatically reduced by salinity, with the S-S roots long less than $10 \%$ of $\mathrm{O}-\mathrm{O}$ ones in all cultivars. Thus, the ratio between shoot and root lengths was generally increased in all cultivars by both salinity and osmotic stresses at any time of stress occurrence (i.e. O-S, S-O and S-S treatments), but the increase was much higher for salinity than for osmotic stress and maximum in S-S treatment (on average, more than three-fold for salt and just
$+19 \%$ for osmotic stress as compared to the O$\mathrm{O}$ treatment). No relevant differences were recorded between cultivars for the variation of shoot and root length of any stressed treatment (i.e. O-S, S-O and S-S) as compared to the never stressed control (O-O).

The Relative Growth Rates (RGRs) calculated between the start and the end of the growth period were always negative for dry weights in both salt and osmotic stressed S-S treatments and for root lenghts in salt stressed S-S and O-S treatments (Tab. 3). The RGR for dry weights was always lower in any stressed treatment than in $\mathrm{O}-\mathrm{O}$ in both experiments on salinity and osmotic potential. On the contrary, the RGRs for fresh weights and for shoot and root lengths were always higher in S-O than in $\mathrm{O}-\mathrm{O}$ in both experiments, and also in osmotic stressed S-S than in O-O. The variation of RGRs for any stressed treatment as compared to the 
correspondent RGRs of O-O often showed slight differences between cultivars (Tab. 3). Only the decrease of RGR for Excalibur dry weight in both salt and osmotic stressed S-S was much greater than for other cultivars. In general, Exagone RGRs in O-S and S-S as compared to O-O decreased more than for Saturnin in the experiment on salinity, while they decreased less $(\mathrm{O}-\mathrm{S})$ or increased more (S-O, S-S) than for Saturnin in the experiment on osmotic stress.

\section{Discussion}

The cultivars Exagone, Excalibur, Toccata and Saturnin were chosen from the screening to continue the study due to multiple reasons. Each of them showed a similar performance in both stressing conditions (i.e. tolerance for Exagone and Excalibur and sensitivity for Toccata and Saturnin). The couple Exagone and Toccata had almost equal seed size, and also Excalibur and Saturnin seeds were not much different, so seed size could not account for the different germination performance at least within each couple (Pandya et al., 1973). An additional advantage of this choice was they were all hybrids, thus each of them was expected to be uniform and easier to study also in case of future investigation on genetic aspects involved in the different stress tolerance.

The cultivar Exagone was highly salt stress tolerant, more than expected from previous experiments with other rapeseed cultivars (AlThabet et al., 2004) and halophytes (Vicente et al., 2004). Its osmotic stress tolerance was also high and in line with that reported by Willenborg et al. (2004) and Andalibi et al. (2005). As compared to the same literature above, the sensitivity of Saturnin was slightly lower for salinity and much higher for osmotic stress. On the same basis, Excalibur could be considered quite tolerant, Toccata quite sensitive.

From an agronomic point of view, the difference of 0.2-0.3 MPa for germination between Exagone and Saturnin would correspond to a difference in soil water content of around 3-5 percent points (by volume), equivalent to $30-50$ $\mathrm{m}^{3} \mathrm{ha}^{-1}$ in the top $0.10 \mathrm{~m}$ soil layer (i.e. $3-5 \mathrm{~mm}$ of water). Consider that in Italy, with a sowing date in half September and an average evapotranspiration of around $0.5 \mathrm{~mm} \mathrm{~d}^{-1}$ (based on average reference potential evapotranspiration in September and considering a crop coefficient of 0.35) (www.ucea.it) it takes around one week to evaporate that water volume. This means that the level of water stress tolerance of Exagone would increase the chances for crop establishment when sown in late summer in soils with moderate water deficiency as it can occur after an occasional rainfall in August-September, and/or trusting in occasional/little rainfall after sowing as it can be expected to occur in September. Similar benefits can derive from the higher tolerance to salinity that is in turn related to the soil water content.

Standing the different stress tolerance of cultivars during germination, the slight differences in their response to stress for seedling growth was not expected (Tabb. 2 and 3). In particular, it was the sensitivity of Exagone and that of Excalibur that was not expected. On the other hand the fairly good performance of Saturnin and Toccata in the S-O treatment would indicate that even a very high salinity during germination did not cause any irreversible damage to stress sensitive seeds. The increase of RGRs for fresh weights in S-O in both experients and in osmotic stressed S-S as compared to O-O suggests that an osmotic adjustment occurred during germination in stressing conditions. Differences in dry weights for the experiment of salinity might be partly accounted for by differences between cultivars on ions accumulation (Blumwald, 2000). This hypothesis would be suggested by the slighter differences recorded between Exagone and Saturnin for fresh weights of salted treatments and for dry and fresh weights in the experiment on osmotic potential. However, this assumption cannot be confirmed in lack of analyses on the ions content of dry matter.

In any case, all growth parameters indicate that Exagone seedlings were not the most stress tolerant, rather their sensitivity to salinity was quite high, while Saturnin seedlings were not the most sensitive. For sure, Excalibur was the most depressed by permanent stress (i.e. S-S) under both salinity and low osmotic potential.

The reduced growth of seedlings in salt stress conditions observed for the four cultivars is in line with findings of Badruddin et al. (2005). The reduction of growth in water stressed seedlings reflects what observed for salt stress and is in 
agreement with findings by Issarakraisila et al. (2007) on other Brassica species. However the effect of water stress was slighter, in lack of the additional toxic effect associated to ions uptake (Kafkafi and Bernstein, 1996). The increase of shoot/root length ratio with salinity would confirm findings by Jamil et al. (2006) on rapeseed and by Kaya and Ipek (2003) on safflower but is in conflict with other evidences reported for many species (Munns, 2002), Brassica ones included (Jamil et al., 2005; Badruddin et al., 2005). Similarly, the increase of shoot/root ratio in water stressed seedlings is in conflict with most literature that reports a sensible reduction of this ratio in Brassica species grown at low osmotic potentials (Kauser et al., 2006; Maggio et al., 2004).

Differences are probably due to the level and timing of stress application and to additional experimental conditions (e.g. growth medium, light and temperature regimes, air $\mathrm{RH} \%$, etc.). In particular, the dramatic reduction of root growth in salted treatments is likely due the toxic effect of the saline solution that was directly in contact with roots, contrarily to what it would happen if the growth medium includes matricial components that may have a buffer effect. Similarly, for osmotic stressed treatments, a certain shoot growth could have been allowed by the high air humidity present into the boxes, while root growth could have been limited to the upper soil layer kept wet by supplying the little water volume from the top of the pot.

The negative RGR values for dry weights in both salt and osmotic stressed S-S treatments and for root lenghts in salt stressed S-S and O$\mathrm{S}$ treatments indicate that those stressing conditions were extremely severe and would have led to seedling death in short time (Tab. 3).

\section{Conclusions}

The different degree of stress tolerance observed among rapeseed cultivars for germination was in the order of $150 \mathrm{mMol}$ for $\mathrm{NaCl}$ concentration and 0.2-0.3 $\mathrm{MPa}$ for osmotic potential, and this may have important agronomic implications. In fact, with tolerant cultivars like Exagone the crop might have higher chances to establish even when sown just after a scarce rainfall and/or relying in a scarce or light rain- fall after sowing. Nonetheless, a higher stress tolerance during germination not necessarily implies a concordant tolerance during the next seedling growth. With this regard, cultivars did not differ substantially for growth parameters of seedlings exposed to stressing conditions, and in some cases cultivars with higher tolerance during germination (i.e. Exagone and Excalibur) resulted even more sensitive during growth, especially under salt stress. The severe stresses applied reduced seedling growth, and root more than shoot growth.

Further studies had been planned and are currently carried out to investigate on the physiological and genetic aspects involved in the different tolerance of cultivars during both germination and seedling growth.

\section{Acknowledgment}

We gratefully acknowledge Prof. Egidio Ciriciofolo for scientific and financial support and Mr. Silvano Locchi for technical assistance.

\section{References}

Al-Thabet S.S., Leilah A.A., Al-Hawass I. 2004. Effect of $\mathrm{NaCl}$ and incubation temperature on seed germination of three canola (Brassica napus L.) cultivars. Scientific Journal of King Faisal University, 5:81-92.

Anastasi U., Santonoceto C., Monti M. 2003. Growth and yield water status and use of spring and winter rapeseed in relation to time of sowing. Proceedings of the $11^{\text {th }}$ International Rapeseed Congress, Copenaghen, 6-10 July 2003, 3:805-807.

Andalibi B., Zangani E., Nazari A.H. 2005. Effects of water stress on germination indices in six rapeseed cultivars (Brassica napus L.). Iranian Journal of Agricultural Sciences, 36:457-463.

Athar H., Ashraf M. 2005. Photosynthesis under drought stress. In: Pessarakli M. (ed.): Hand Book Photosynthesis, 795-810. CRC Press, New York, USA.

Badruddin M., Rhaman M.M., Nehar N.A., Hossain M.M., Hasan M.B. 2005. Physiological characterization of mustard (Brassica sp.) genotypes for their salt tolerance. Pakistan Journal of Biological Sciences, 8 , 3:433-438.

Blackshaw R.E. 1991. Soil, temperature and moisture effects on downey brome vs. winter canola, wheat and rye emergence. Crop Sci., 21:1034-1040.

Blumwald E. 2000. Sodium transport and salt tolerance in plants. Curr. Opin. Cell. Biol. 12:431-434.

Bradford M. 1995. Water relations in seed germination. 
In: Kigel J., Galili M. (eds.): Seed Development and Germination, 351-396. M. Dekker, New York, 1995.

Coolbear P., Francis A., Grierson D. 1984. The effect of low temperature pre-sowing treatment on the germination performance and membrane integrity of artificially aged tomato seeds. J. of Exp. Bot., 35:1609-1617.

Issarakraisila M., Ma Q., Turner D.W. 2006. Photosynthetic and growth responses of juvenile Chinese kale (Brassica oleracea var. alboglabra) and Caisin (Brassica rapa subsp. parachinensis) to waterlogging and water deficit. Scientia Horticulturae, 111:107-113.

Jamil M., Lee C.C., Rehman S.U., Lee D.B., Ashraf M., Rha E.S. 2005. Salinity $(\mathrm{NaCl})$ tolerance of Brassica species at germination and early seedling growth. Electronic Journal of Environmental, Agricultural and Food Chemistry, 970-976.

Jamil M., Lee D.B., Yung K.Y., Ashraf M., Lee S.C., Rha E.S. 2006. Effect of salt $(\mathrm{NaCl})$ stress on germination and early seedling growth of four vegetables species. Journal of Central European Agriculture, 7, 2:273281.

Kafkafi U., Berstein N. 1996. Root growth under salinity stress. In: Waisel Y., Eshel A., Kafkafi U. (eds): Plant roots: the hidden half, 435-452. Marcel Dekker, New York.

Kauser R., Athar H., Ashraf M. 2006. Chlorophyll fluorescence: a potential indicator for rapid assessment of water stress tolerance in canola (Brassica napus L.). Pakistan Journal of Botany, 38, 5:1501-1509.

Kaya M.D., Ipek A. 2003. Effects of different soil salinity levels on germination and seedling growth of safflower (Carthamus tinctorius L.). Turk. J. Agric. For., 27:221-227.

King J.R., Kondra Z.P., Thiagarjah M.R. 1986. Selection for fast germination in rapeseed (Brassica napus $L$. and B. campestris L.). Euphytica, 35:835-842.
Maggio A., De Pascale S., Ruggiero C., Barbieri G. 2004. Physiological response of field-grown cabbage to salinity and drought stress. Europ. J. of Agron., 23:57-67.

Munns R. 2002. Comparative physiology of salt and water stress. Plant Cell and Environment, 25:239-250.

Pandya R.B., Khan M.I., Gupta S.H., Dhindsa K.S. 1973. Effect of seed size upon germination, moisture uptake, seedling growth, dry weight changes and soluble sugars under polyethylene glycol $(\mathrm{Peg})$ induced stress. Biochemie und Physiologie der Pflanzen, 164, $1: 80-87$.

Tei F., Ciriciofolo E. 1997. Germinazione sotto condizioni di stress osmotico in crocifere da orto. Sementi elette, 43, 3/4:53-60.

Ungar I.A. 1995. Seed germination and seed-bank ecology of halophytes. In: Kigel J., Galili G. (eds.): Seed Development and Germination, 599-628. Marcel Dekker Inc. New York.

Vicente O., Boscaiu M., Naranjo M.A., Estrelles E., Bellès J.M., Soriano P. 2004. Responses to salt stress in the halophyte Plantago crassifolia (Plantaginaceae). Journal of Arid Environments, 58:463-481.

Willenborg C.J., Gulden R.H., Johnson E.N., Shirtliffe E.N. 2004. Germination characteristics of polymercoated canola (Brassica napus L.) seeds subjected to moisture stress at different temperatures. Agron. J., 96:786-791.

Wurr D.C., Fellows J.R 1985. A determination of the seed vigour and field performance of crisp lettuce seedstocks. Seed Sci \& Technol, 13:11-17.

\section{Websites}

http://www.ucea.it/ 